\title{
Strategic of Remuneration in Public Management: Inefficiency of the Programs as a Result of Theoretical Negligence
}

\author{
Luis Claudio de Jesus Silva, Antonio Luiz Marques, Paulo César Diniz de Araújo, André Luiz Nunes Zogahib \\ Universidade Federal de Minas Gerais, Belo Horizonte, Brazil \\ Edgar Reyes Junior \\ Universidade Federal de Roraima, Boa Vista, Brazil
}

\begin{abstract}
The purpose of this study is to analyze the impacts of individual motivation in strategic remuneration policies aimed at providing more effectiveness to public organizations. Cannot be ignored the differences that make each individual unique. If the goal is to provide greater motivation and individual performance improvement as a condition for greater organizational efficiency is necessary to observe the provisions of the economic psychological theories and self-determination. The accelerated automation of labor, decreasing of the size of the companies, the increase of the service sector, the marked demographic changes, and the speed with which changes are occurring in companies mainly in last decade, have demanded from the organizations the confrontation of these continues and varied changes. It is in this scenario of intense mutation, that is seen the emergence of new approaches in the management of people, especially the strategic policies of remuneration, both in the private and in public organizations. Most OECD countries, with a significant number of in developing countries have adopted policies for strategic use of remuneration. However, it should be noted that incentive systems efficient and effective in a particular organizational context may be ineffective or counterproductive when deployed in a different organizational context. The failure of strategic compensation programs in some countries can be associated with ignorance or neglect of managers with theoretical precepts, becoming indispensable in deepening studies that provide greater insight into the issue and its impact on the motivation and behavior of individuals.
\end{abstract}

Keywords: strategic compensation, public sector, theoretical negligence

\section{Introduction}

The intense changes caused by the globalized world, strongly felt by the business organizations in recent decades have caused changes in the paradigms until then unquestioned. Surviving these changes has required organizations an examination for the enhancement of its human resources and the constant search for alternatives that promote a balanced organizational environment that makes organizations more productive, competitive, and perennial.

Luis Claudio de Jesus Silva, Doctoral candidate, Administração Department, Universidade Federal de Minas Gerais. Antonio Luiz Marques, Doctor of Administration, Administração Department, Universidade Federal de Minas Gerais. Paulo Cesar Diniz de Araújo, Doctoral candidate, Administração Department, Universidade Federal de Minas Gerais. André Luiz Nunes Zogahib, Doctoral candidate, Administração Department, Universidade Federal de Minas Gerais. Edgar Reyes Junior, Doctor of Administration, Administração Department, Universidade Federal de Roraima.

Correspondence concerning this article should be addressed to Luis Cláudio de Jesus Silva, Rua Eduardo Ribeiro, 417, São Francisco. CEP: 69.305-140, Boa Vista, Roraima, Brasil. E-mail: luisclaudiojs@gmail.com. 
In response to these changes in the external environment, many organizations began to seek a management more professional and flexible by adopting policies of strategic planning and systemic and comprehensive management. And in this context of extreme competition realizes the urgent need to attract and retain human resources motivated, competitive and able to assist in maximizing organizational performance. Aiming at these goals, organizations have deployed strategic policies of compensation and have been testing various ways to reward efficiently the effort of workers, maintaining or providing greater motivation, commitment to organizational goals, improvement in performance and as a consequence of the reduction in staff turnover, absenteeism, and increasing positive social perception.

The scenario can be seen in private organizations, more flexible and agile in responding to changes. In the Brazilian public organizations, bureaucratic and inflexible, little has been done to respond to external changes and meet the new demands of society. There are perceptible experiments, still incipient, of implementation of strategic management planning, however, mostly without the understanding necessary for a systemic and integrative. In the public sector, not identified, for example, an efficient policy of valuing staff and that is able to follow the adopted models and experiences in private organizations or public organizations that joined in the models of new public management, even partially, in several parts of the world.

In many cases, practices aiming to improve performance in the public sector by the adoption of strategic models of remuneration, search theoretical studies on motivation only reasons that will validate and give credibility to the proposed model, neglecting theoretical assumptions necessary for understanding the many variables that often prevent the success of the models and repeat the cycle of inefficient management and increased government spending

Sailing in a vast ocean of literature, fishing in the depths, or sometimes even on the surface, the lesson conveyed by various theorists will bring a little more light to the lighthouse that will guide the understanding of the theme.

\section{From the New Models of Public Management to the Payment by Performance}

The search for greater efficiency is at the center of contemporary debates in public management. Governments worldwide have adopted reforms to improve the effectiveness and responsiveness of public services (Batley \& Larbi, 2004).

Chanlat (2002) attributes this transformation of public administration to the crisis of the welfare state, the collapse of the socialist experiments and the hegemony of private enterprise—as an organizational model and how efficient market model-significantly affect not only the vision of public action, but also policies, programs, structures, and the culture of organizations. Paula (2007) emphasizes that this new management model is the result of the attempt to adapt and transfer the knowledge managerial developed in the private sector for the public sector.

Following these changes comes the New Public Management (NPM), proposed by Thatcher and Reagan in the early 1980s. However, the NPM cannot even be considered as an overall reform program or doctrine, but more probably an abbreviation for a group of administrative doctrines that have figured prominently in the bureaucratic reform agenda in several member countries of the Organization for Economic Co-operation and Development (OECD), resulting in many doctrinal components of professional management of public organizations, such as explicit and measurable standards of performance, greater emphasis on output controls, shift to disaggregation of units and increased competition with greater emphasis on discipline and use of the 
resources (Hood, 1996).

Within this context, the agenda of New Public Management with its policy of individualization and flexibility in contractual relations have become common. Currently, two thirds of OECD countries and a growing number of developing countries, using employment contracts based on outcomes and some form of variable pay for performance, for example, Brazil, Mexico, Netherlands, New Zealand, United Kingdom, United States, and Canada (OECD, 2005; Pacheco, 2010).

In theory, all OECD member countries have some sorts of system of pay for performance (OECD, 2004). However, in practice, only a few can be considered possessor of reward systems that operate as a real incentive, that is the payment is related to an evaluation of performance as a result, not previously known. In many countries, by contrast, rewards for performance are often distributed without any formal evaluation of individual performance (OECD, 2004). In other cases, pay for performance systems are simply grafted on to existing pay systems (Ingraham, 1996).

The introduction of incentives - by performance - in the public sector is subjected to a level of uncertainty and opportunistic defections much more significant than in the private sector. It is difficult to suppose that public organizations can accurately measure individual performance, team or unit and that payment can be administered in order to capitalize the value expected by potential recipients (OECD, 2005).

The OECD acknowledges that the implementation of incentives can generate insecurity among employees and that the lack of confidence is one of the most serious obstacles to the implementation of incentive systems, and relies systems that pay for performance should be applied in environments that maintain and provide support for a working relationship based on trust and that certain prerequisites are essentials before introducing a system of pay for performance, some of them are, transparency within the organization, clear promotion mechanisms, and trust in managers (OECD, 2004).

But another warning emphasized in the literature points to a basic problem of credibility between superiors and subordinates (Miller, 2000), independently of the existence of intermediate layers or third parties such as unions or courts. Because of this position, the interests of those who take benefits from the incentives (owners) should be relatively different from the interests of those who manage the system of incentives (managers). Similarly the incentives in the public sector are more likely to be implemented in government where there is a relative separation between those who takes benefits from the incentives (the politicians) and those who manage the system of incentives (government employees) (Dahlström \& Lapuente, 2009).

The OECD, by analyzing the failure of pay for performance systems, recognizes that the politicization is one of the main obstacles to the development of systems and objective evaluation of performance. Public employees are more likely to accept pay for performance, while recognizing that incentives can sometimes be disadvantageous for them when they fail to achieve the proposed objective, if they feel the process of distribution of incentives is "fair". The OECD, explicitly states that "where the level of political appointments is high", is more difficult to define a system of pay for performance and this impedes the perception of the politicization as a mechanism of "procedural fairness" and probably the system will result in demotivation of servers (OECD, 2004, p. 39).

The payment as an incentive for improving the performance cannot be indiscriminately and widely offered to all employees. In this sense, Buelens and Van Den Broeck (2007) and Weibel et al. (2009), warn that the officials of lower level in public administration are more likely to find their work less interesting than those in positions of management and are therefore ideal candidates to the system of pay for performance. The nature of 
these tasks are not intrinsically rewarding, and in these cases, pay for performance tends to greatly increase extrinsic motivation, without the risk of reducing intrinsic motivation. On the other hand, pay for performance, in the case of interesting/challenging tasks, can affect individual performance (Perry, Mesch, \& Paarlberg, 2006). For the public administration, the consequences of this second view are undoubtedly more severe than for the private sector for two reasons. First, the ongoing reforms of the public sector is targeted, mainly, to high public officials (OECD, 2005). High officials, however, are more likely to work on interesting tasks than other servers, the content of the work tends to be larger, requiring more responsibility and is more challenging. The disregard of that argument can direct pay for performance for the wrong recipients.

Notwithstanding the difficulties mentioned remain the belief on the assumption that human behavior can be directed through the selective deployment of rewards or sanctions, some theoretical trends say that individuals will perform better when they relate systems of incentives and rewards, as well as possible, to their own performance. This position is supported by the behavioral management theory which argues that the pay for performance increases personal efforts and thereby individual performance (Luthans \& Kreitner, 1985; Lehman \& Geller, 2004).

The literature also indicates a beneficial side effect of the pay for performance systems: They are a significant window of opportunity for the introduction of many other reforms (OECD, 2004). That is, where the incentives work other reforms-NPM-tends to work too.

Pay for performance is only one way of the proposed strategic for a compensation system. The relevance of these systems to the success of remuneration programs and maximizing organizational efficiency justify their separate analysis, in the next topic.

\section{Remuneration Systems}

During the construction of the referential on remuneration systems, there are two main difficulties: First, commonly, some theories are concerned with the consequences produced by the remuneration system on people and their performance. While others, approach the determinants of the remuneration, system considering it as a cause; the second difficulty relates to the integration of these theories since they are originated from different areas of knowledge (economics, psychology, sociology, administration), each one with its referential and visions of man or human nature.

In the first case, the failure to observe may confuse the researcher and his analysis. However, the going further in the two sections demonstrated that both are equally valid, if the compensation system can have an impact on individuals and their efforts (motivational theories) and also receive the influence of certain variables (economic, for example) (Plothow, 2006).

In the face of the numerous variables, both determinants and the consequences, is choose to restrict the approach only to the variables directly related to issues discussed in this essay. Among the determinants, is highlighted:

(1) The social contract: It is believed that from certain rules of equal treatment, justice, and rights, the human being tend to have cooperative behaviors, believing that the motivator is the collective behavior. It is expected, so that managers act in accordance with the collective interests, since everyone will be affected by them. To Plothow (2006), remuneration is set according to the standards of work, and justice according to law, will be seen as fair;

(2) Economic theories: Start from the assumption that the homo economicus, who is presumed as rational, 
will seek to maximize their gains and minimize their efforts, being moved by incentives (financial or not). It is believed that man is moved by the "value" that attaches to the incentives. This vision of man is opposed to the underlying vision of the theory of social.

To Aguiar (2009), the individuals' preferences in the process of efforts' allocation between different tasks, depend on incentive factors (return value and instrumentality) and cognitive factors (evaluation period, the reference point, and sense of self effectiveness), rather than just reflect the effects of incentives, as admitted by the normative economic literature;

(3) Theory of competition: Assumes that motivation does not occur because of the individual's level of remuneration, but by what is paid for higher levels of the career or of the hierarchy. Thus, if the relative differences are not seen as significant, they may affect the performance. The theory highlights the effect that the remuneration of top executives may have on the behavior of other employees (Bloom \& Milkovich, 1996).

About the consequences, the choice of emphasis is on variables associated with transaction costs:

(1) Costs to monitor the time and effort: It is believed that the employed will strive more and more if being monitored and thus generate more results. However, there will always be a cost involved in the control and monitoring of employees, since the employee can "stall" or do what is unexpected. To Plothow (2006), the variable portion of the compensation system attaches to the role of replacing the mechanisms of monitoring and control, exercised by the supervision. This way, if the result of the work is easily measured and consequently reduces the need for control it is possible to remunerate them by the results they produced, that is, so predominantly variable or performance. On the other hand, it is believed that the organizations that monitor their employees can pay less for the same effort. However, if monitoring costs are high, firms should focus on variable remuneration, worrying about the result produced without observing the effort, that are difficult to measure (John \& Weitz, 1989).

(2) Disutility of effort/work: It is believed that the employee prefers the leisure over the work and financial remuneration must compensate the effort expended in order to maximize it (Feder, 2005). In contrast, Willamson (1985) and Feder (2005) postulates that "liking the work" would nullify this effect, since the effort does not depend on the financial incentive.

(3) Heterogeneity of workers: It is believed that a staff of heterogeneous and with a homogenous remuneration policy or with emphasis on the fixed portion, it may be perceived as unfair to those workers with high performance, leading them to leave the organization, remaining the underperforming ones. Some authors defend the idea that offering variables incentives retain skilled workers, which contributes to maximizing organizational results (Feder, 2005).

Many authors that have analyzed the relationship between remuneration and performance proceeded on the assumption that the remuneration system is an essential mechanism, since that, individual efforts are directed toward goals of the strategic business and when structured properly, this process can contribute to increase the organizational performance (Gomez-Meija \& Welbourne, 1998).

The next topic proposes the review of the inexhaustible theme of motivation, the focus will not be in the repetitive descriptions of the most popular theories, of those will be presented only a summary. The proposal is to bring to the debate theories and positions often neglected by managers of remuneration systems and in many cases explain their failure. 


\section{Human Motivation}

The discussions about motivation, by its importance for individuals and organizations—and in the relationships between them —are extensive and heated, and often begin with the questions brought by Bowditch and Buono (2002): "What makes some people give their all while others seek only to do the minimum required?”, and "how can I influence the performance of those who work for me?”. For Davis and Newstrom (1989), motivation is fundamental to the perfect progress of the organization, no matter how much technology and equipment have an organization, these things cannot be put into use unless they are led and guided by people who are motivated. In fact, how to stimulate the motivation of people is a permanent challenge of management activity.

There is vast literature about theories that attempts to explain human behavior in the relationship between motivation, effort, and performance. For the reasons already listed, will be done only a summary of the theories most known and used:

(1) Theory of expectation: Stands out as one explanatory studies about motivation and the more accepted today. Notwithstanding its critics, many studies give basement (Robbins, 2002). In the theory of Victor Vroom, motivation is seen as a process that can determine the choices between different possibilities of behavior of the individual, assessing the consequences, all alternatives of action and satisfaction will be seen as resulting from the relationship between expectation—developed by the individual—and expected results (Vroom, 1964; Ferreira et al., 2006).

(2) Theory of socially acquired needs: David McClelland, based on the identification of three basic needs that people develop: need for achievement, power, and affiliation. According to Bowditch and Buono (2002), McClelland's theory proposes that each individual will be at different times, influenced by one of these three factors, and the strength of each specific need — and its influence on our behavior—will vary according to the situation.

(3) Equity theory: The basis of the theory is that people compare the proportion between their inputs (effort, experience, education, competence) and results (rewards, remuneration, raises, recognition) with the input relations—results of other people be seen as comparable (Bowditch \& Buono, 2002). In this comparison, is implied that search for a fair and equitable treatment (Bergamini, 1997).

To Ferreira et al. (2006), in organizational terms, the theory has a strong relationship with the remuneration, distribution of benefits and/or recognition among employees. It warns that if these processes are not well managed can undermine the social climate of the organization, contributing to creating a work place where there is a perception of injustice and therefore without stimulus for motivation.

(4) Two-factor theory: Herzberg's research suggested that motivation is composed of two dimensions, not related: hygiene factors related to aspects of extrinsic to the task, in other words, aspects of the work and activities that can prevent dissatisfaction, but that not influence the employees to grow and develop; motivational factors related to the position held by the employee and include: recognition and opportunity of professional progress, responsibility and achievement, freedom to create, innovate, among other factors intrinsic to their work and that can lead employees of states of non-fulfillment to the state of satisfaction (Bowditch \& Buono, 2002).

(5) Setting of goals theory: By this theory, the definition of goals to be accomplished has the potential to energize people as they guide their thoughts and focus their efforts toward reaching their goals. These goals 
should have characteristics which could lead to a higher level of motivation (energy) must be acceptable and not confront personal values-has to make sense for the individual. The objectives should be ambitious, specific and measurable. Set goals with employees' participation increases the acceptance and generates commitment. Be clear in what is expected of an employee tends to produce better results than simply determine that to do their better (Cavalcanti, 2005).

The following approaches transcribe theoretical lessons poorly distributed—or even known—and often neglected by managers of pay for performance systems in the public sector:

(6) The social cognitive theory: In communion with the theory of goal setting, predicts that the effect of setting goals on the level of motivation of individuals is enhanced when information about performance are made available (Bandura, 2004), in other words, different dimensions of performance information, with emphasis on timing and frequency, tend to affect the way individuals react to this information (Ilgenetal, 1979; Aguiar, 2009).

The dimensions highlighted are interrelated and ensure that performance information provided in a stable and close to the action are indispensable for the achievement of goals be successful (Fried \& Slowik, 2004). Bandura (2004) reinforces the importance of timeliness of information in order to create opportunities for people to correct their behavior while still in progress. This fact would be impossible if the performance information was available long after the action.

Is suitable to warn that although the references of the positive effects of the dimensions, listed on the behavior of individuals, other studies lead to divergent paths. Chhokar and Wallin (1984) and Aguiar (2009), in an experiment, found that weekly performance information does not result in performance improvements when compared with information available in every two weeks. In the same sense, Lurie and Swaminathan (2009) suggest a negative effect on performance caused by frequent performance information, when the environment is characterized as uncertain. Increased frequency of performance information would lead people to an excessive focus on the latest information that will also result in difficulty in comparing the information received over several periods (Lurie \& Swaminathan, 2009).

(7) Determination theory and economic psychology: Ryan and Deci (2000) argue that people need to feel competent and self-determined to be intrinsically motivated. Contradict the ideas of other theories that all behavior would be the result of the satisfaction of physiological needs and propose the concept of "basic psychological needs" as determinants of intrinsically motivated behavior.

The economic psychology and self-determination theory suggests that motivation is not a unitary phenomenon. Individuals may not only have different levels of motivation, but also experiment with different types of motivation because of specific characteristics of the organizational context and job characteristics. Extrinsic motivation indirectly satisfy personal needs, that is extrinsic motivation refers to doing something that leads to results which are separable, as monetary compensation (Ryan \& Deci, 2000). With money you cannot produce direct utility, but it allows the individual to acquire desired products. Intrinsic motivation, on the other hand, directly meets personal needs (Frey \& Jegen, 2001), creating an intrinsic reward for those who perform the tasks.

According to Weibel, Rost, and Osterloh (2009) is acknowledged that employees are often at a high level, intrinsically motivated, in other words, they perform their duties because of loyalty by an internalized sense of duty (Perry, 2000; Vandenabeele, 2007). It is proposed that intrinsic motivation, under certain conditions, can be undermined by pay for performance system: give someone a monetary incentive for the performance of 
something that is already enjoyed can decrease your motivation to doing so, the person probably will not see it as a attractive his internal action be externally driven.

(8) Theory of motivation crowding: According to Jegen and Frey (2001), the theory assumes the existence of values that are no longer being from the moment they are given a price and that there are provisions for cooperation that are not compatible with trade or coercion, suggesting that external intervention via monetary incentives or punishments may change the levels of intrinsic motivation of individuals. These changes are called crowding-in when an external stimulus or punishment leads the individual to increase the product of a task or the provision of goods and crowding-out when the activity or material support decreases as a result of the reward/incentive or punishment.

It is noteworthy that the type of external intervention is not represented only by monetary incentives, but also, for example, by some kind of control mechanism and organizational norms. The adoption of any of these incentives, by the public manager is directed to crowding-in -in other words, come to the meeting of the intrinsic motivation of employees. Crowding-out effects are unwanted because discourage agents which generate reactions that are not desired by the manager.

Based on the theory, Weibel et al. (2009) point out five reasons for the modest success of pay for performance systems in the public sector. In the first place, it seems that the public sector intrinsic motivation is high (Houston, 2000; Buelens \& Van Den Broeck, 2007). So the pay for performance system can potentially create a strong crowding-out effect. Second, public funding is clearly more limited than the private sector financing. As a result, and as suggested by a number of studies, the effect of the price on pay for performance management in the public sector tends to be quite small (Kellough \& Lu, 1993), while the crowding-out effect tends to be significantly higher in the case of tasks potentially interesting and inherently rewarding. In third place, pay for performance can reduce investment in political expertise and select the wrong type of employees (Gailmard \& Patty, 2007). Fourth, the problem of multitasking (Holmström \& Milgrom, 1991) may represent an additional difficulty for the implementation of pay for performance in the public sector-pay for performance requires accurate measurement of performance and allocation of this performance to individual efforts to be effective.

Weibel et al. (2009), conducted research aiming to identify the cause of pay for performance, sometimes negatively affect the personal efforts. And, based on the theory of self-determination (Deci, Koestner, \& Ryan, 1999) and on the crowding theory (Frey \& Jegen, 2001) propose that the payment related to the performance both produce a cognitive change and amplifies the reward meaning for the individual behavior, in other words, produces an effect of crowding-in. At the same time reduce the meaning of the content of the own work for the behavior, in other words, produces a crowding-out effect. The overall effect of pay for performance therefore, is dependent on the strength of these two effects.

\section{Concluding Remarks}

The intense competition caused by the global economy finds no borders and affects all countries. Staying competitive is essential for the survival of organizations, requiring proactive attitudes in order to rethink the business models until now unquestioned, planning the future in a strategic and systemic way and capable of integrating all sectors of the organizational structure, including there the people management policies. However, in this scenario, traditional forms of management are inefficient to attend to the new organizational needs.

In many countries, the search for greater efficiency has led public managers to propose the inclusion of 
monetary incentive systems as a reward for improvement in organizational performance index. However, there is no more room for the adoption of reward systems ruled only on the description of activities or responsibilities of the position - common in bureaucratic models of management. The demand requires the deployment of strategic remuneration more dynamic and flexible with a focus on overall objectives of organizations. However, the public sector has specific characteristics that may restrict the adoption of naive performance incentives according to those prevailing in the private sector. Effective and efficient systems in an organizational context may be ineffective or even counterproductive when implemented in a different organizational context. Besides, these difficulties, the look on the "why" the failure of some programs, indicates a significant unprepared managers that neglect some approaches and keep the focus excessively on the consequences but without analyzing the causes of the resulting behavior.

Cannot be overlooked the fact that the inclusion of performance incentives produces a significant cognitive change and that unfortunately if not treated properly can lead to individual or group to the dissatisfaction, and contaminate the whole system of incentives of the organization. The economic psychology points to the need for a closer look at studies such as the self-determination theory and the theory of motivation crowding, as indispensable to structure the decision making in the adoption of models of performance incentives, and in the analysis and systematic comprehension of the results produced.

Studies indicate the inconsistency of generalization of the pay for performance. Not all servers can be achieved by the same incentive system. "One size shirt does not fit in everyone”. Beyond individual differences: values, expectations, goals, etc., Which directly influence the motivation—and that can be minimized when in groups/team — should be considered the intrinsic motivation produced by the challenge of the job and the wealth of motivational tasks. That is, in cases where the intrinsic motivation is high, the insertion of an incentive for the performance-extrinsic motivation—can have a disastrous effect, undermining the existing motivation producing suspiciousness and a big reduction of the self-esteem. All these factors should be investigated and be the object of a deep and careful analysis before making a decision for inclusion of incentives for the organization.

When complete, is suitable to recognize that although the motivation is among the most discussed and theorized topics in distinct scientific fields, much remains to be explored. The most important objective of this study was to keep the debate on pay for performance systems, as a remuneration strategy in public organizations, and how this has affected the motivation of servers and the service improvement. In this sense, even without the intention of proposition of models, remain the alert to the need of more studies, not restricted to the administration science, seeking in the comprehension of the causes and not in the consequences answers to the behavior changes on human motivation.

\section{References}

Aguiar, A. B. (2009). Sistemas de Remuneração Gerencial e orientação temporal dos gestores. TESE (Doutorado em Ciências Contábeis). Faculdade de Economia, Administração e Contabilidade, Universidade de São Paulo, São Paulo.

Bandura, A. (2004). Self-efficacy: The exercise of control. New York: W. F. Freeman and Company.

Batley, R., \& Larbi, G. (2004). The changing role of government: The reform of public services in developing countries. London, UK: Palgrave Macmillan.

Bergamini, C. W. (1997). Motivação nas organizações (4th ed.). São Paulo: Atlas.

Bloom, M. C., \& Milkovich, G. T. (1996). Issues in managerial compensation research. Journal of Organizational Behavior, 3, 23-47.

Bowditch, J. L., \& Buono, A. F. (2002). Elementos do Comportamento Organizacional. São Paulo: Ed. Pioneira Thomson. 
Buelens, M., \& Van Den Broeck, H. (2007). An analysis of differences in work motivation between public and private sector organizations. PublicAdministrationReview, 67, 65-74.

Cavalcanti, V. L. (2005). Liderança e Motivação. Rio de Janeiro: FGV.

Chanlat, J. F. (2002). O gerencialismo e a ética do bem comum: A questão da motivação para o trabalho nos serviços públicos. Retrieved October 15, 2012, from http://unpan1.un.org/intradoc/groups/public/documents/CLAD/clad0043316.pdf

Chenhall, R. H. (2003). Management control systems design within its organizational context: Findings from contingency-based research and directions for the future. Accounting Organizations and Society, 28, 127-168.

Chhokar, J. S., \& Wallin, J. A. (1984). A field study of the effect of feedback frequency on performance. Journal of Applied Psychology, 69(3), 524-530.

Dahlström, C., \& Lapuente, V. (2009). Explaining cross-country differences in performance-related pay in the public sector. Journal of Public Administration Research and Theory, 20(3), 309-332.

Dart, R. (2004). Being "business-like” in a nonprofit organization: A grounded and inductive typology. Nonprofit and Voluntary Sector Quarterly, 23, 290-310.

Davis, D., \& Newstrom, J. W. (1989). Human behavior at word. New York: McGraw-Hill.

Deci, E. L., Koestner, R., \& Ryan, R. (1999). The undermining effect is a reality after all—Extrinsic rewards, task interest, and selfdetermination: Reply to Eisenberger, Pierce, and Cameron (1999) and Lepper, Henderlong, and Gingras (1999). Psychological Bulletin, 125, 692-700.

Feder, R. (2005). Remuneração variável: Um teste do modelo do táxi em uma empresa brasileira. Faculdade de Economia, Administração e Contabilidade: Universidade de São Paulo. São Paulo,

Ferreira, A., Fuerth, L. R., \& Esteves, R. C. P. M. (2006). Fatores de Motivação no Trabalho: O Que Pensam os Líderes. In Proceedings from 30 EnAnpad: Encontro da Associação Nacional de Pós-Graduação em Administração, Rio de Janeiro.

Frey, B., \& Jegen, R. (2001). Motivation crowding theory: A survey of empirical evidence. Journal of Economic Surveys, 15(5), 589-611.

Fried, Y., \& Slowik, L. H. (2003). Enriching goal-setting theory with time: An integrated approach. Academy of Management Review, 29(3), 404-422.

Gailmard, S., \& Patty, J. (2007). Slackers and zealots: Civil service, policy discretion, and bureaucratic expertise. American Journal of Political Science, 51, 873-889.

Gomez-Meija, L., \& Welbourne, T. (1998). Compensation strategy: An overview and future steps. Human Resouce Planning, 11, 173-189.

Holmström, B., \& Milgrom, P. (1991). Multitask principal-agent analyses: Incentive contracts, asset ownership, and job design. Journal of Law, Economics and Organization, 7, 24-52.

Hood, C. (1996). Exploring variations in public management reform of the 1980s. In H. Bekke, J. Perry, \& T. Toonen (Eds.), Civil service systems in comparative perspective (pp. 268-287). Bloomington: Indiana University Press.

Houston, D. J. (2000). Public-service motivation: A multivariate test. Journal of Public Administration Research and Theory, 10, 713-728.

Ingraham, P. W. (1996). The reform agenda for national civil service systems: External stress and internal strains. In H. Bekke, J. Perry, \& T. Toonen (Eds.), Civil service systems in comparative perspective (pp. 247-267). Bloomington: Indiana University Press.

John, G., \& Weitz, B. (1989). Salesforce compensation: An empirical investigation of factors related to the use os salary versus incentive compensation. Journal of Marketing Research, 26, 1-14.

Kellough, J. E., \& Lu, H. (1993). The paradox of merit pay in the public sector: Persistence of a problematic procedure. Review of Public Personnel Administration, 13(2), 45-64.

Lehman, P., \& Geller, E. S. (2004). Behavior analysis and environmental protection: Accomplishments and potential for more. Behavior and Social Issues, 13, 13-32.

Lurie, N. H., \& Swaminathan, J. M. (2009). Is timely information always better? The effect of feedback frequency on decision making. Organizational Behavior and Human Decision Processes, 108, 315-329.

Luthans, F., \& Kreitner, R. (1985). Organizational behavior modification and beyond: An operant and social learning approach. Glenview, I.L.: Scott Foresman.

Miller, G. J. (2000). Above politics: Credible commitment and efficiency in the design of public agencies. Journal of Public Administration Research and Theory, 10, 289-328. 
Moynihan, D. P. (2006). Managing for results in state government: Evaluating a decade of reform. Public Administration Review, 66, 77-89.

OECD. (2004). Performance-related pay policies for government employees: Main trends in OECD member countries. Paris: OECD Publishing.

OECD. (2005). Performance-related pay policies for government employees. Paris: OECD Publishing.

Pacheco, R. S. (2010). A agenda da nova gestão pública. In M. R. Loureiro, F. L. Abrucio, \& R. S. Pacheco (Eds.), Burocracia e política no Brasil-Desafios para o Estado Democrático no Século XXI (pp. 183-218). Rio de Janeiro: FGV Editora.

Paula, A. P. P. (2007). Por uma nova gestão pública: Limites e potencialidades da experiência contemporânea. Rio de Janeiro: Editora FGV.

Perry, J. L. (2000). Bringing society in: Toward a theory of public-service motivation. Journal of Public Administration Research and Theory, 10, 471-488.

Perry, J. L., Mesch, D., \& Paarlberg, L. (2006). Motivating employees in a new governance era: The performance paradigm revisited. Public Administration Review, 66, 505-514.

Plothow, C. B. A. (2006). Fatores contingenciais à estratégia de remuneração da força de vendas (Dissertação, Faculdade de Economia, Administração e Contabilidade, Universidade de São Paulo).

Pontes, B. R. (2002). Administração de cargos \& salários (9th ed.). São Paulo: LTr.

Ryan, R. M., \& Deci, E. L. (2000). Intrinsic and extrinsic motivations: Classic definitions and new directions. Contemporary Educational Psychology, 25(1), 54-67.

Vandenabeele, W. (2007). Toward a public administration theory of public service motivation. Public Management Review, 9, 545-556.

Vroom, V. H. (1964). Work and motivation. New York: John Wiley \& Sons.

Weibel, A., Rost, K., \& Osterloh, M. (2009). Pay for performance in the public sector-Benefits and (hidden) costs. Journal of Public Administration Research and Theory, 20, 387-412.

Willamson, O. E. (1985). The economic institutions of capitalism. New York: Free Press. 